\title{
A DIFERENÇA ENTRE O FALAR E O AGIR: ANÁLISE DO DECRETO 9.656/2018
}

\author{
THE DIFFERENCE BETWEEN SPEAKING AND ACTING: AN ANALYSIS OF \\ DECREE 9.656/2018
}

\author{
Fabiane Ferreira da Silva Moraes* \\ Eliesi Graciele de Souza**
}

\section{Resumo}

A história dos sujeitos surdos é marcada por preconceitos linguísticos e culturais que se desdobraram em inúmeras barreiras comunicacionais e atitudinais. Desse modo, cada documento oficial que aborda a temática da língua de sinais é recebido como uma vitória e um avanço para a comunidade surda. Este trabalho avalia a publicação oficial mais recente sobre essa temática: o Decreto 9.656/2018, que altera o Decreto 5.626/2005. Para tanto, será realizada uma pesquisa qualitativa, de caráter documental. A análise dos dados será ancorada na fundamentação teórica da Análise do Discurso de linha francesa. Os resultados apontam que a publicação permitiu ao enunciador criar a imagem de preocupação com os sujeitos surdos. A análise também evidenciou que algumas das medidas listadas já constavam em legislações anteriores.

Palavras-chave: Surdos. Língua de Sinais. Análise do discurso.

\section{Introdução}

Segundo o Censo realizado em 2010 pelo Instituto Brasileiro de Geografia e Estatística (IBGE), no Brasil há 9,7 milhões de pessoas com deficiência auditiva. O Decreto 5.626/2005, define como surdo aquele que tem perda auditiva bilateral, parcial ou total e, por isso, utiliza Libras para se comunicar. Os surdos compreendem e interagem com o mundo a partir das visualizações.

Dentre os documentos oficiais que abordam a temática da Língua Brasileira de Sinais (Libras) optamos, nesta pesquisa, analisar o Decreto 9.656/2018, que altera o Decreto 5.626/2005. Esse último regulamenta a Lei 10.436/2002, e o art. 18 da Lei 10.098/2000. Essa

\footnotetext{
* Mestrado em Letras pela Universidade Federal da Grande Dourados (UFGD), Dourados, Mato Grosso do Sul, Brasil. E-mail: fabianemoraes@ufg.br

** Graduanda em Letras Tradução e Interpretação em Libras/Português pela Universidade Federal de Goiás (UFG), Goiânia, Goiás, Brasil. E-mail: graciele1425@ hotmail.com
} 
escolha se deu por ser o documento mais recente que aborda o assunto dos direitos da comunidade surda.

Fundamentado na Análise do Discurso (AD) de Linha Francesa, o trabalho objetiva analisar as construções discursivas sobre as políticas públicas voltadas para o atendimento de pessoas surdas e com deficiência auditiva no corpus selecionado. Desse modo, apresentaremos no tópico que segue alguns dos conceitos que nortearão a pesquisa, fundamentados nas proposições de Charaudeau (2011), Orlandi (2001, 2003) e Brandão (2009). Considerando a extensa literatura que trata do surgimento da Análise do Discurso e de suas diferentes vertentes teóricas, nos deteremos na descrição dos conceitos que nortearão a análise do corpus.

\section{Fundamentação teórica}

De acordo com Orlandi (2003) a Análise do Discurso se interessa pelos efeitos de sentido entre interlocutores. Ou seja, uma simples imagem, um simples gesto que produz sentido (ex: dedo indicador sob os lábios com a palma da mão para medial) podem produzir sentidos e serem objeto de investigação e interpretação. Esses sentidos ocorrem devido às vivências e experiências de cada indivíduo e são carregados de significados. Para compreender a língua fazendo sentido para o homem e para sua história, é importante perceber como a linguagem está na ideologia e como se mostra na língua.

Dentre os conceitos fundamentais da AD estão o discurso, a linguagem e a ideologia. Para Charaudeau (2011) "o discurso é um percurso de significância que se acha inscrito num texto, e que depende de suas condições de produção e dos locutores que o produzem e o interpretam”. Em toda e qualquer prática de linguagem, há discurso. Sendo que a linguagem é uma atividade exercida entre falantes, apenas o ser humano é capaz de se comunicar pela linguagem verbal, ajustando-a de acordo com a ocasião.

Segundo Orlandi (2001, p. 15) "[...] a palavra discurso, etimologicamente, tem em si a idéia de curso, de percurso, de correr por, de movimento. O discurso é assim palavra em movimento, prática de linguagem: com o estudo do discurso observa-se o homem falando". De modo semelhante, Brandão (2009) afirma que o discurso é a palavra em movimento, ou seja, as interações verbais ou não verbais, escritas, faladas e dialogadas. Também há discurso no momento em que se lê um livro, assiste-se a um filme, a um musical, a uma peça de teatro ou escuta-se uma música, independente do gênero. 
Para Brandão (2009) a ideologia é o conjunto de atitudes, representações ou imagens que os falantes têm sobre o interlocutor, sobre si mesmos e sobre assuntos em questão. A ideologia está relacionada com a posição social de onde os sujeitos falam ou escrevem. Já o conceito de texto pode ser compreendido como uma forma de concretização do discurso. Para produzir ou compreender um texto, deve-se analisar suas condições de produção: quais valores e crenças, aspectos históricos, sociais e políticos os interlocutores carregam. Além dos conhecimentos linguísticos (vocabulário, gramática, regras morfológicas e sintáticas) da língua; é necessário ter conhecimentos extralinguísticos (conhecimento de mundo, enciclopédico, históricos, culturais, ideológicos, entre outros) para a produção/compreensão do texto.

\section{Metodologia}

Conforme exposto por Gil (2002) a pesquisa é o processo racional e sistemático que tem por o objetivo possibilitar respostas aos problemas encontrados. Ela se faz necessária quando não possuímos respostas para esses problemas, ou quando essas respostas não estão claras.

A presente pesquisa é qualitativa e de caráter documental. Flick (2013) explica que "a pesquisa qualitativa não está moldada na mensuração como acontece nas ciências sociais". A pesquisa documental "vale-se de materiais que não recebem ainda um tratamento analítico, ou que ainda podem ser reelaborados de acordo com os objetos da pesquisa" (GIL, 2002, p. 45). Até o momento não constam publicações acadêmicas sobre o documento a ser analisado.

O corpus selecionado é composto pelo caput e pelos três parágrafos do primeiro artigo do Decreto 9.656/2018. A seleção do excerto se baseou em alguns critérios, a saber: pelas escolhas lexicais, por ser um documento que altera o artigo 26 Decreto 5.626/2005 e por ser a publicação mais recente, e por isso pouco discutida, sobre o uso e difusão da Libras. A análise comparativa com o Decreto 5.626/2005 justifica-se já que o corpus selecionado altera o decreto que regulamentou a Lei da Libras.

\section{Análise do Decreto 9.656/2018}

O Decreto 9.656 foi publicado em 27 de dezembro de 2018, ou seja, nos últimos dias do mandato do presidente Michel Temer, momento em que o país enfrentava uma crise econômica e política. Vale lembrar que, ao enunciar produzimos sentidos não apenas sobre o que é dito, mas também sobre nós mesmos. Carvalho (2012, p. 87-88) analisou os documentos 
oficiais sobre os surdos e concluiu que a publicação de tais documentos permite que o enunciador, no caso o presidente da república, elabore duas imagens de si. A primeira é como aquele que "impõe as regras, que institui as normas para que sejam garantidos os direitos aos surdos e o outro, que se mostra solidário e responsável por esse sujeito a ser amparado, por demonstrar a preocupação em atender todas as parcelas da sociedade, dentre eles, os surdos". A mesma realidade descrita por Carvalho também pode ser identificada no corpus aqui analisado.

A publicação trouxe alterações e acréscimos ao Decreto 5626/2005, por isso, para compreensão do documento faz-se necessário analisá-lo à luz da legislação anterior. A primeira alteração listada no decreto pode ser observada na tabela que segue:

\begin{tabular}{|c|c|}
\hline Decreto 5.626/2005 & Decreto 9.656/2018 \\
\hline $\begin{array}{l}\text { Art. 26. A partir de um ano da publicação } \\
\text { deste Decreto, o Poder Público, as empresas } \\
\text { concessionárias de serviços públicos e os } \\
\text { órgãos da administração pública federal, } \\
\text { direta e indireta devem garantir às pessoas } \\
\text { surdas o tratamento diferenciado, por meio do } \\
\text { uso e difusão de Libras e da tradução e } \\
\text { interpretação de Libras - Língua Portuguesa, } \\
\text { realizados por servidores e empregados } \\
\text { capacitados para essa função, bem como o } \\
\text { acesso às tecnologias de informação, } \\
\text { conforme prevê o Decreto n }{ }^{\circ} 5.296 \text {, de } 2004 .\end{array}$ & $\begin{array}{l}\text { Art. 26. O Poder Público, as empresas } \\
\text { concessionárias de serviços públicos e os } \\
\text { órgãos da administração pública federal, } \\
\text { direta e indireta, deverão garantir às pessoas } \\
\text { surdas ou com deficiência auditiva o seu } \\
\text { efetivo e amplo atendimento, por meio do uso } \\
\text { e da difusão da Libras e da tradução e da } \\
\text { interpretação de Libras - Língua Portuguesa. }\end{array}$ \\
\hline
\end{tabular}

Se por um lado o decreto de 2005 afirma que a garantia ao atendimento às pessoas surdas deveria acontecer a partir de um ano de sua publicação, por outro lado, o decreto de 2018 entra em vigor na data de sua publicação, conforme consta em seu segundo artigo. Ainda que o fato de não haver o prazo estendido para o início das medidas descritas traga o sentido de uma positividade, o primeiro documento estabelecia o prazo de um ano para que as empresas e os órgãos da administração se adequassem. Ou seja, o que é descrito no artigo já estava em vigor desde 2006.

A comparação entre os dois decretos evidencia três alterações textuais: a primeira refere-se ao acréscimo das pessoas "com deficiência auditiva" dentre aquelas que devem ter a garantia de atendimento adequado. Em segundo lugar há a substituição da expressão 
“tratamento diferenciado" pela construção "efetivo e amplo atendimento". A substituição realizada remete para escolhas lexicais que priorizam o politicamente correto. Sob esse aspecto, Carvalho (2012, p. 80) afirma que os documentos oficiais "têm o cuidado de selecionar termos que se referem aos surdos de acordo com o que é considerado politicamente correto em determinado momento histórico". Depreende-se então que a escolha lexical aceita em 2005 passou a ser vista como incorreta no contexto histórico de 2018.

Por fim, há a exclusão da garantia de que tal atendimento seja realizado "por servidores e empregados capacitados para essa função, bem como o acesso às tecnologias de informação, conforme prevê o Decreto $\mathrm{n}^{\circ}$ 5.296, de 2004". Tais alterações levantam o questionamento sobre se seria possível o amplo e efetivo atendimento sem a presença de servidores e empregados capacitados para essa função, como previa o decreto de 2005.

Os parágrafos seguintes, nos dois decretos, detalham quais as medidas a serem adotadas para assegurar o atendimento às pessoas surdas ou com deficiência auditiva. A tabela a seguir apresenta o texto do primeiro parágrafo:

\begin{tabular}{|l|l|}
\hline \multicolumn{1}{|c|}{ Decreto 5.626/2005 } & \multicolumn{1}{|c|}{ Decreto 9.656/2018 } \\
\hline $\begin{array}{l}\S 1^{\text {o }} \text { As instituições de que trata o caput } \\
\text { devem dispor de, pelo menos, cinco por cento } \\
\text { de servidores, funcionários e empregados } \\
\text { capacitados para o uso e interpretação da } \\
\text { Libras. }\end{array}$ & $\begin{array}{l}\text { 10 Para garantir a difusão da Libras, as } \\
\text { instituições de que trata o caput deverão } \\
\text { dispor de, no mínimo, cinco por cento de } \\
\text { servidores, funcionários ou empregados com } \\
\text { capacitação básica em Libras. (Redação dada } \\
\text { pelo Decreto } n^{\circ} \text { 9.656, de 2018). }\end{array}$ \\
\hline
\end{tabular}

Chama a atenção o fato de que enquanto o texto de 2005 mostra que os servidores, funcionários e empregados deveriam ser "capacitados para o uso e interpretação da Libras", o texto de 2018 afirma que esses devem ter "capacitação básica em Libras". Ou seja, o excerto mostra que, com a capacitação básica em Libras, seria possível garantir a difusão da língua de sinais. Ainda que a difusão do conhecimento básico possa ocorrer, vale destacar que, para que aconteça de fato a inclusão/comunicação, a formação básica é insuficiente.

O artigo $6^{\circ}$ da Lei 12.319/2010 que dá direito ao profissional Tradutor e Intérprete da Língua Brasileira de Sinais (TILS) de atuar, ao tratar das atribuições desse profissional descreve que: 
Art. $6^{0}$ São atribuições do tradutor e intérprete, no exercício de suas competências:

I - efetuar comunicação entre surdos e ouvintes, surdos e surdos, surdos e surdos-cegos, surdos-cegos e ouvintes, por meio da Libras para a língua oral e vice-versa;

II - interpretar, em Língua Brasileira de Sinais - Língua Portuguesa, as atividades didático-pedagógicas e culturais desenvolvidas nas instituições de ensino nos níveis fundamental, médio e superior, de forma a viabilizar o acesso aos conteúdos curriculares;

III - atuar nos processos seletivos para cursos na instituição de ensino e nos concursos públicos;

IV - atuar no apoio à acessibilidade aos serviços e às atividades-fim das instituições de ensino e repartições públicas; e

V - prestar seus serviços em depoimentos em juízo, em órgãos administrativos ou policiais.

Diante disso, entende-se que a formação mais aprofundada faz-se necessária, pois a capacitação básica não é suficiente para o profissional atuar como tradutor intérprete de Libras/português, sendo eficaz somente nos casos de comunicação informal com o sujeito surdo, pois o ato de interpretar vai muito além de uma simples comunicação, envolvendo domínio das línguas, conhecimento de culturas, competências interpretativa e tradutória, ética profissional, capacidade lexical, capacidade de adaptação do discurso. Por se tratar de uma língua viva, com estrutura gramatical própria necessita-se de domínio em todas as áreas mencionadas anteriormente.

É interessante observar também que a construção textual traz o efeito de sentido de que cabe às instituições a difusão da Libras, já que são as instituições que "deverão dispor" de servidores com capacitação básica em Libras. Cita-se como exemplo dessas instituições os postos de saúde, assistência social, delegacias, CRAS, CREAS, entre outros. Contudo, na prática, são os servidores, funcionários e empregados que deverão agir (participar de cursos e formações) para atender esse público. Essa situação reflete o exposto por Charaudeau (2006, p. 253), quando esse autor afirma que todo ato de linguagem é um agir sobre o outro, que consiste em "colocar o outro em uma posição de obrigação a ser executada, em uma relação de submissão à posição do sujeito que fala".

Todavia, para que esses profissionais sejam capacitados, é necessário que sejam disponibilizados cursos de formação, bem como que sejam viabilizadas condições para que os servidores participem dos referidos cursos. A vivência no espaço acadêmico possibilitou a percepção de que, muitas vezes isso não ocorre na área de assistência social universitária, por 
exemplo. Muitas vezes, ao requerer bolsas de assistência estudantil, os sujeitos surdos não conseguem uma efetiva comunicação, já que os servidores não são capacitados mesmo para uma comunicação básica em Libras. Ademais, o segundo parágrafo do Decreto 9.656/2018 acrescentou a seguinte construção textual:

$\S 2^{\circ}$ Para garantir o efetivo e amplo atendimento das pessoas surdas ou com o atendimento das pessoas surdas ou com deficiência auditiva, o Poder Público, as empresas concessionárias e permissionárias de serviços públicos e os órgãos da administração pública federal, direta e indireta, poderão utilizar intérpretes contratados especificamente para essa função ou central de intermediação de comunicação que garanta a oferta de atendimento presencial ou remoto, com intermediação por meio de recursos de videoconferência on-line e webchat, à pessoa surda ou com deficiência auditiva.

Para tanto, em situações específicas do parágrafo $2^{\circ}$ fica claro que a presença do tradutor intérprete se torna indispensável. Desse modo, a capacitação básica apontada no artigo $1^{\circ}$ do Decreto 9.656/2018 não é recomendada. Ao permitir a intermediação por meios tecnológicos são desconsideradas algumas situações que podem ocasionar prejuízos, devido a falhas como: falta de bateria em um dispositivo, falta de sinal ou sinal fraco de rede ou internet, as variações linguísticas, entre outros.

Além dos entraves listados anteriormente, chama a atenção o fato de que em 2013 o governo federal criou trinta e sete Centrais de Interpretação de Libras (CIL) em diversos estados brasileiros. Desde então, várias outras centrais foram implementadas nas unidades federativas. As CIL oferecem o atendimento presencial e também o atendimento virtual, através "de chat de comunicação, em que o intérprete se comunica com o surdo a distância, e também agenda atendimentos em saúde, como consultas médicas, atendimento jurídico e alguns serviços como o bancário" (BRASIL, 2013). Em outras palavras, o atendimento via "central de intermediação" não é uma medida nova para garantir o amplo e efetivo atendimento. Em seguida, o parágrafo terceiro detalha:

\begin{tabular}{|c|l|c|}
\hline \multicolumn{2}{|c|}{ Decreto 5.626/2005 } & \multicolumn{2}{|c|}{ Decreto 9.656/2018 } \\
\hline $\begin{array}{l}\S \text { o O Poder Público, os órgãos da } \\
\text { administração pública estadual, municipal e } \\
\text { do Distrito Federal, e as empresas privadas }\end{array}$ & $\begin{array}{l}3^{\text {o }} \text { O Poder Público, os órgãos da } \\
\text { distrital e as empresas concessionárias e e }\end{array}$ \\
\hline
\end{tabular}


que detêm concessão ou permissão de serviços públicos buscarão implementar as medidas referidas neste artigo como meio de assegurar às pessoas surdas ou com deficiência auditiva o tratamento diferenciado, previsto no caput. permissionárias de serviços públicos buscarão implementar as medidas referidas neste artigo como meio de assegurar às pessoas surdas ou com deficiência auditiva o efetivo e amplo atendimento previsto no caput."

Convém sublinhar que, ao se referir que os órgãos e empresas de serviço público, o documento diz que estas "buscarão implementar" as medidas listadas no decreto. A construção textual traz o efeito de sentido de uma tentativa, uma possibilidade de que as medidas como meio de assegurar às pessoas surdas ao efetivo e amplo atendimento ocorra, e não uma garantia para tal. Para tanto, poderiam ter sido utilizada as expressões como "deverão implementar", "implementarão", "obrigatoriamente serão implementadas", comprometendo-se então o poder público para que a referida medida de fato fosse executada. Logo, apenas buscar implementar as medidas do decreto não é o suficiente para garantir às pessoas surdas um atendimento efetivo, pois caso este não ocorra, elas não terão em que se embasar para exigir, tendo em vista o termo que foi utilizado no decreto - buscarão.

Assim sendo, o que está exposto no decreto se refere a diferentes formas de dizer o que as legislações anteriores já asseguravam, pois como diz Mariani (1999, p. 108), “os sentidos das palavras podem mudar conforme a situação em que são usadas e conforme o lugar social ocupado pelo sujeito que fala". Dessa maneira, observando que se busca entender quais são os sentidos construídos, pode-se notar que, como afirma Soares (2007, p. 183), "os sentidos vão se estabelecendo através de já ditos ou já construídos, ora retomando discursos em forma de paráfrase e reproduzindo sentidos, ora em uma disputa acirrada de efeitos discursivos".

\section{Considerações finais}

A história dos sujeitos surdos é marcada por preconceitos linguísticos e culturais que se desdobraram em inúmeras barreiras comunicacionais e atitudinais. Diante dessa realidade, cada documento oficial que aborda a temática da língua de sinais é recebido, via de regra, como uma vitória e um avanço para a comunidade surda. No entanto, a análise do corpus possibilitou a compreensão de que nem sempre uma nova publicação significa um avanço, sendo que, muitas vezes, o que prevalece é o dito de outra forma. 
As considerações sobre o documento analisado podem ser melhor compreendidas à luz das proposições de Charaudeau (2006, p. 258) sobre a palavra política de decisão, definida como "essencialmente uma palavra de ação que é fundada sobre uma posição de legitimidade". Por isso, optamos por finalizar o artigo tendo como base os três aspectos que tal palavra indica.

Primeiramente a palavra de decisão, tal como exposto por Charaudeau (2006) "diz que há uma desordem social (uma situação, um fato, um acontecimento), o qual é julgado inaceitável (ele escapa a uma norma social ou ao quadro jurídico existente, caso contrário, bastaria aplicar a lei): ela enuncia a afirmação: ‘as coisas não vão bem”” (p. 259). No caso do Decreto 9.656/2018 a desordem pode ser compreendida como a falta de atendimento amplo e efetivo para o público-alvo do documento. De fato, a observação da realidade de atendimento aos sujeitos surdos demonstra que "as coisas não vão bem".

Em segundo lugar, ela aponta que "é preciso tomar uma atitude para resolver essa anormalidade e reinseri-la em uma nova ordem ou em um novo quadro jurídico; ela enuncia uma afirmação de ordem deôntica: "devemos consertar as coisas"” (p. 260). Assim como exposto durante a análise, a publicação do decreto permitiu ao presidente em exercício em 2018 enunciar não apenas sobre uma desordem, mas também criar uma imagem de si como alguém preocupado em "consertar as coisas" para os sujeitos surdos.

Por fim, a palavra de decisão "revela ao mesmo tempo que medida deve ser adotada no instante mesmo de sua enunciação (é seu caráter performativo)". No caso do corpus são apresentadas duas medidas diferentes: a primeira é a disponibilização de "cinco por cento de servidores, funcionários ou empregados com capacitação básica em Libras" e a segunda a "utilização de intérpretes contratados especificamente para essa função ou central de intermediação de comunicação que garanta a oferta de atendimento presencial ou remoto, com intermediação por meio de recursos de videoconferência on-line e webchat".

Quanto às medidas a serem adotadas, foi possível identificar que elas já constavam nas legislações anteriores e que as CILS já haviam sido implementadas no território nacional. Em alguns aspectos, como no parágrafo primeiro, ao que parece, o texto do decreto de 2005 seria mais adequado para a difusão da Libras e atendimento dos sujeitos surdos.

Não tivemos a pretensão de esgotar todos os sentidos que constam no corpus, antes, assim como expresso por Orlandi, procuramos fazer uma leitura menos ingênua do texto publicado. Esperamos que as reflexões apresentadas possam contribuir, ainda que timidamente, com as discussões sobre as práticas inclusivas para os sujeitos surdos. 


\begin{abstract}
The history of deaf people is marked by linguistic and cultural prejudices that unfolded in innumerable communicational and attitudinal barriers. Faced with this reality, each official document that addresses the issue of sign language is generally received as a victory and a breakthrough for the deaf community. This work assesses the most recent official publication on the subject - Decree 9.656 / 2018, which amends Decree 5,626 / 2005. In order to do that, a qualitative, documentary research will be carried out. The analysis of the data will be anchored in the theoretical basis of the French Discourse Analysis. The results indicate that the publication allowed the enunciator to create the image of concern for deaf subjects. The analysis also showed that some of the measures listed were already in previous legislation.
\end{abstract}

Keywords: Deaf. Sign Language. Discourse Analysis.

\title{
Referências
}

BRANDÃO, H. H. N. Analisando o Discurso. In: Museu da Língua Portuguesa. São Paulo, 2004. Disponível em: <http://www.museudalinguaportuguesa.org.br/files/mlp/ texto_1.pdf>. Acesso em: 10 jun. 2019.

BRASIL. Lei $\mathrm{n}^{\circ}$ 10.436, de 24 de abril de 2002. Dispõe sobre a Língua Brasileira de Sinais Libras e dá outras providências. In: Diário Oficial da União, n. 79, Seção 1, de 25/4/2002. p. 23. Disponível em: <http://pesquisa.in.gov.br/imprensa/jsp/visualiza/index.jsp?jornal=1\& pagina $=23 \&$ data $=25 / 04 / 2002>$. Acesso em: $10 \mathrm{fev} .2019$.

Decreto $\mathrm{n}^{\circ}$ 5.626, de 22 de dezembro de 2005. Regulamenta a Lei $\mathrm{n}^{\circ} 10.436$, de 24 de abril de 2002, que dispõe sobre a Língua Brasileira de Sinais - Libras, e o art. 18 da Lei no 10.098, de 19 de dezembro de 2000. In: Diário Oficial da União, n. 246, Seção 1, de 23/12/2005. p. 28. Disponível em: <http://pesquisa.in.gov.br/imprensa/jsp/ visualiza/index.jsp?Jornal=1\&pagina=28\&data=23/12/2005> . Acesso em: 20 abr. 2019.

Decreto n 9.656 de 27 de dezembro de 2018. Altera o Decreto $\mathrm{n}^{\circ} 5.626$, de 22 de dezembro de 2005, que regulamenta a Lei $\mathrm{n}^{\circ} 10.436$, de 24 de abril de 2002, que dispõe sobre a Língua Brasileira de Sinais - Libras. In: Diário Oficial da União, n. 249, Seção 1, de 28/12/2018,. p. 17. Disponível em: <http://www.in.gov.br/web/dou/-/decreto-n-9-656-de-27de-dezembro-de-2018-57221610>. Acesso em: 20 abr. 2019.

CARVALHO, Lílian Pereira de. Análise discursiva de documentos oficiais sobre o sujeito surdo. 2012. 145 f. Dissertação (Mestrado em Ciências Humanas) - Universidade Federal de São Carlos, São Carlos, 2012.

CHARAUDEAU, P. O discurso político. In: EMEDIATO, Wander; MACHADO, Ida Lúcia; MENEZES, William (org.). Análise do discurso: gêneros, comunicação e sociedade. Belo Horizonte: UFMG, 2006. 
FLICK, U. Introdução à metodologia de pesquisa: um guia para iniciantes. Porto Alegre: Penso, 2013.

GIL, A. C. Como elaborar projeto de pesquisa. São Paulo: Atlas, 2002.

MARIANI, B. S. C. Políticas de colonização linguística. In: Letras, Santa Maria, n.27, p. 73 82, 2003.

ORLANDI, E. P. Análise de Discurso: princípios e procedimentos. Campinas: Pontes, 2001.

A Análise de Discurso em suas diferentes tradições intelectuais: o Brasil. 2003. In: Anais do I Seminário de Estudos em Análise do Discurso. Porto Alegre: UFRGS, 2003. Disponível em: <http://anaisdosead.com.br/1SEAD/Conferencias/EniOrlandi.Pdf>. Acesso em: 12 jun. 2019.

SOARES, A. S. F. O discurso jornalístico e seus rituais. In: Eco-pós, n.2, p. 181-196, 2007 